\title{
The Effect of Co-solvent on Esterification of Oleic Acid Using Amberlyst 15 as Solid Acid Catalyst in Biodiesel Production
}

\author{
Iwan Ridwan, Mukhtar Ghazali, Adi Kusmayadi, Resza Diwansyah Putra, Nina Marlina, and Eko Andrijanto*
}

Chemical Engineering Department, Politeknik Negeri Bandung, Indonesia

\begin{abstract}
The oleic acid solubility in methanol is low due to two phase separation, and this causes a slow reaction time in biodiesel production. Tetrahydrofuran as co-solvent can decrease the interfacial surface tension between methanol and oleic acid. The objective of this study was to investigate the effect of co-solvent, methanol to oleic acid molar ratio, catalyst amount, and temperature of the reaction to the free fatty acid conversion. Oleic acid esterification was conducted by mixing oleic acid, methanol, tetrahydrofuran and Amberlyst 15 as a solid acid catalyst in a batch reactor. The Amberlyst 15 used had an exchange capacity of $2.57 \mathrm{meq} / \mathrm{g}$. Significant free fatty acid conversion increments occur on biodiesel production using co-solvent compared without co-solvent. The highest free fatty acid conversion was obtained over methanol to the oleic acid molar ratio of $25: 1$, catalyst use of $10 \%$, the co-solvent concentration of $8 \%$, and a reaction temperature of $60^{\circ} \mathrm{C}$. The highest FFA conversion was found at $28.6 \%$, and the steady state was reached after 60 minutes. In addition, the use of Amberlyst 15 oleic acid esterification shows an excellent performance as a solid acid catalyst. Catalytic activity was maintained after 4 times repeated use and reduced slightly in the fifth use.
\end{abstract}

\section{Introduction}

Biodiesel is the renewable fuels that not only have great demand, but also pollutants emit less. In biodiesel production, feedstock must be cheap, sustainable and non-edible oil because it can decrease the biodiesel production cost [1-5]. Biodiesel is produced by esterification with acid catalyst and transesterification by the alkaline catalyst. Unfortunately, in transesterification process with an alkaline catalyst, the presence of free fatty acid (FFA) in oil causes saponification reaction between FFA and alkaline catalyst which decrease the biodiesel yield and increase the production cost. Hence, the esterification with acid catalyst must be done before transesterification process to minimize the FFA content in the transesterification reaction. In esterification, the FFA is converted to fatty acid methyl ester (biodiesel). Even though transesterification and esterification are different reactions, it produces the same product namely biodiesel.

Biodiesel production can be influenced by those variables such as co-solvent, amount of catalyst, reaction temperature, reaction time, and the molar ratio of reactant [6-10]. Yunus et al. studied these variables effect to FFA conversion. The FFA conversion using waste cooking oil as a feedstock was $88 \%$ under a reaction temperature of $60^{\circ} \mathrm{C}$, methanol to oil mass ratio of $18: 1$, catalyst amount of $3.0 \%$ and stirring speed of $300 \mathrm{rpm}$ [11]. Another study [12] reported that the optimum conditions for the esterification were achieved at $70^{\circ} \mathrm{C}$ of reaction temperature, $5 \%$ of catalyst loading and $6: 1$ of ethanol to the oleic acid molar ratio by using the zeolite prepared from kaolin and achieved FFA conversion $85 \%$ after 60 min [12]. Solid catalysts such as Amberlyst 15 made the highest FFA conversion than the others at catalyst amount $(1-2 \% \mathrm{wt})$ and temperature $50-60^{\circ} \mathrm{C}$ in esterification [6].

Another problem in biodiesel production is the oil has very low miscibility in methanol [13]. The low miscibility of methanol in oil causes low overall reaction rate. Co-solvent can decrease the interfacial surface tension and increase the reaction rate. Boocock et al. [9] reported that tetrahydrofuran (THF) is the best choice to co-solvent due to its boiling point $\left(67^{\circ} \mathrm{C}\right)$ is almost the same with the methanol boiling point $\left(64^{\circ} \mathrm{C}\right)$. The loading of THF is for improving the overall reaction rate in both transesterification and esterification [14]. Hence, this study aims to investigate the effects of co-solvent,

\footnotetext{
Corresponding author: andrijanto.2002@gmail.com
} 
catalyst amount, reaction temperature and the ratio of methanol to oleic acid for esterification using Amberlyst 15 as a solid acid catalyst in the production of biodiesel.

\section{Materials and Methods}

\subsection{Materials}

Oleic acid was purchased from a local supplier (PT. Bratachem), and Methanol (99.8\% purity) was purchased from Merck. Amberlyst 15 was used as the solid acid catalyst to improve reaction time and THF as co-solvent to enhance the miscibility of oil and the methanol. Isopropyl alcohol, toluene, potassium hydroxide and phenolphthalein were used to analyze FFA content.

\subsection{Methods}

\subsubsection{Preparation of Catalyst}

This preparation aims to activate the pores and remove any impurities that attached to the catalyst. Amberlyst 15 was soaked in methanol and chloride acid $(\mathrm{HCl})$ solution for 1 hour. Afterward, it was heated in the oven at $85^{\circ} \mathrm{C}$ for 1 hour.

\subsubsection{Determination of ion exchange capacity}

This step is to measure the acid capacity of the catalyst. Amberlyst 15 was soaked into $\mathrm{HCl}$ solution for 1 hour, and after that, the catalyst was dried in the oven at $90^{\circ} \mathrm{C}$ for $2 \mathrm{~h}$. The dried catalyst was then soaked in $\mathrm{NaCl}$ solution for $24 \mathrm{~h}$ to add sodium ion to the solution. After that, the $0.01 \mathrm{M} \mathrm{NaOH}$ was used to titrate the solution using phenolphthalein as an indicator to determine the titration point. The determination of ion exchange capacity (IEC) is determined by equation [17]:

$$
\mathrm{IEC}=\frac{\text { Volume of } \mathrm{NaOH} \times \text { Concentration of } \mathrm{NaOH}}{\text { Weight of catalyst }}
$$

\subsubsection{Esterification}

The oleic acid esterification in this study was conducted in a batch reactor by mixing oleic acid, methanol, Amberlyst 15 and THF. The reflux condenser was equipped the reactor recovery the remaining methanol. The temperature controller and water bath were equipped to the reactor to control the desired temperature. An agitator was used to mix the solution at $400 \mathrm{rpm}$. The investigated factors in this study were the co-solvent amount, catalyst loading, the methanol to oil molar ratio, and reaction temperature.

A $50 \mathrm{ml}$ of oleic acid was fed to the reactor for each experiment. Esterification process was carried out in the oleic acid to methanol molar ratio 1:5, 1:10, 1:15, 1:20 and 1:25. The amount of Amberlyst 15 was $2 \% \mathrm{w}, 4$ $\% \mathrm{w}, 6 \% \mathrm{w}, 8 \% \mathrm{w}$ and $10 \% \mathrm{w}$. The temperature varied was $30^{\circ} \mathrm{C}, 40^{\circ} \mathrm{C}, 50^{\circ} \mathrm{C}$ and $60^{\circ} \mathrm{C}$. The amount of co- solvent varied was $2 \% \mathrm{w}, 4 \% \mathrm{w}, 6 \% \mathrm{w}, 8 \% \mathrm{w}$ and $10 \% \mathrm{w}$. Consequently, those variables will be varied to get the optimum condition. Each experiment was conducted for 90 minutes. Sampling was done manually at reaction time every 15 minutes to analyze the FFA concentration.

\subsubsection{The Method of Analysis}

Determination of FFA was analyzed using American Oil Chemists Society (AOCS) method [14]. The sample was taken from the reactor every 15 minutes. One gram of sample was dissolved in $10 \mathrm{ml}$ of toluene and isopropyl alcohol mixture $(1: 1 \mathrm{v} / \mathrm{v})$ as a solvent to ensure the miscibility of sample and titrant. Three drops of phenolphthalein indicator were added to the mixture.

The adding of phenolphthalein was used as an indicator and titrated using $\mathrm{KOH}(0.25 \mathrm{~N})$ solution until the sample changed the pink color. The percentage of the unreacted FFA was calculated using the equation below [6].

$$
F F A(\%)=\frac{\text { Vol. of KOHxNormality KOHx } 28.2}{\text { Weight of sample }} \times 100 \% \text { (2) }
$$

The FFA conversion was determined by the equation given [6].

FFA conversion $(\%)=\frac{(F F A i-F F A t)}{F F A i} \times 100 \%$

where $\mathrm{i}$ is initial concentration, $\mathrm{t}$ is the final concentration in each reaction time.

\subsubsection{Catalyst Reuse}

The method of catalyst reuse was adopted from Hykkerud et al. [15]. The catalyst used in each experiment was collected. Subsequently, those catalysts were soaked in methanol for 60 minutes and heated in the oven to dryness.

\section{Results and Discussion}

\subsection{Ion Exchange Capacity}

The ion exchange capacity demonstrates the ability of the catalyst to increase the conversion of FFA. In a previous study [6], Amberlyst 15 with an ion exchange capacity of $5.2 \mathrm{meq} / \mathrm{g}$ yielded FFA conversion of 35$45 \%$ [6]. Meanwhile, the catalyst used in this study has an exchange capacity $2.57 \mathrm{meq} / \mathrm{g}$. This result is determined by ion exchange method, and this is slightly lower than expected. This is due to the catalyst was stored for a quite long time. The ion exchange capacity will be very influential in converting FFA into biodiesel [11].

\subsection{The Effect of Methanol Molar Ratio}

Biodiesel production from oleic acid with molar ratio variation of methanol to oleic acid was done by 5 variations. The differences of methanol to oleic acid 
molar ratio are 5: 1, 10: 1, 15: 1, 20: 1, and 25: 1 . Methanol was chosen because the methanol reactivity is higher than ethanol as a reactant. Fig. 1 shows the changes of the conversion of the FFA every 15 minutes with reaction time for 90 minutes. The esterification reaction of oleic acid is a reversible reaction. Therefore, excessive use of methanol can shift the equilibrium reaction toward the product. It can be seen in Fig. 1 that there was a significant increase in conversion in a process using THF as a co-solvent compared with a reaction without THF. This suggests that the presence of THF helps the oil and methanol mixture into one phase. It facilitates the reaction between oleic acid and methanol and finally increases the overall reaction rate. Fig. 1 explains that the esterification reaction without THF resulted in a maximum FFA conversion of $3.15 \%$ whereas with THF the conversion increases to $23.16 \%$ at the same reaction time 90 minutes. By comparing with another result [6] for esterification of oleic acid using Amberlyst 15, without using co-solvent, the esterification reaction has reached steady state after 100 minutes while in this research esterification reaction steady state after 75 minutes. This suggests that the THF addition as a co-solvent increase the rate of esterification reaction of oleic acid.

It can be inferred from Fig. 1 that the molar ratio of methanol dramatically influences the conversion of the reaction. The higher mole of methanol causes the higher FFA conversion $[12,16]$. At a 5: 1 to 20: 1 methanol molar ratio, the conversion increased sharply and experienced steady state after 75 minutes. In our study with methanol to oil molar ratio of $25: 1$, produced the highest FFA conversion and steady state is achieved after 60 minutes. The steady state is faster than the previous study, this may due to the role of THF in this reaction by providing single phase system for the reactants although the conversion at this ratio is $23.16 \%$ which is almost half of the previously reported. This is due to the ion exchange capacity of Amberlyst 15 used in this study is smaller $(2.57 \mathrm{meq} / \mathrm{g})$ compared to the earlier reported by Andrijanto et al. which is $4.7 \mathrm{meq} / \mathrm{g}$ [17].

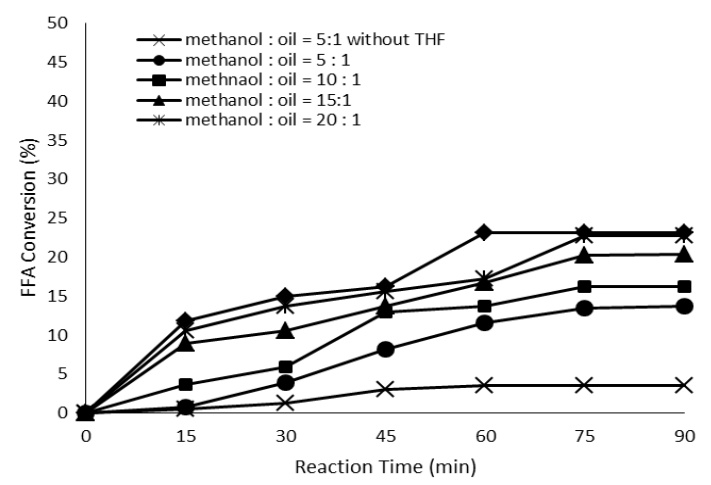

Fig. 1. The Effect of Methanol Molar Ration on FFA conversion

\subsection{The Effect of Catalyst Amount}

The effects of the amount of Amberlyst 15 used on FFA conversion were investigated. The catalyst amount was varied from $2 \%$ to $10 \%$. The temperature of reaction and molar ratio of methanol to oil was kept constant during the experiment. As shown in Fig.2, the FFA conversion changes with time. The conversion increases with the increase of the amount of catalyst.

Fig. 2 indicates the conversion of FFA every 15 minutes at reaction time for 90 minutes. It was clear that the greater the number of catalysts the greater the resulting FFA conversion. The oleic acid esterification is a difficult reaction to occur in the absence of a catalyst, and the conversion is often limited by the nature of the reaction which is reversible. In Fig. 2, it is clear that the oleic acid esterification with $2 \%$ and $4 \%$ catalyst amount resulted in FFA conversion of about $5.14 \%$ to $12.08 \%$ respectively. In addition, at catalyst amount of $6 \%, 8 \%$ and $10 \%$ there was a significant increase of FFA conversion which is $23.16 \%, 25.21 \%, \quad 28.57 \%$ respectively.

At the amount catalyst of $2 \%$, the maximum FFA conversion was $5.47 \%$, and by increasing the catalyst amount to $4 \%$, the conversion was almost doubled which was $12.08 \%$. The steady state condition is reached after 75 min. Further increase the catalyst amount by $6 \%, 8 \%$ and $10 \%$ result in faster steady state, and this achieved after $60 \mathrm{~min}$. It means the steady state condition is faster by adding the amount of catalyst. This is due to the more active site presence (hydrogen ion within the Amberlyst 15 ) in the reaction mixture. The rise in the number of active sites within reaction mixture provided the chance of oleic acid reacted with methanol on the surface of the catalyst and yielded increase reaction rate $[6,11,12]$. The previous result shows that the increases of the catalyst amount above $10 \%$ yield a plateau, which is suggesting that the equilibrium condition is reached.

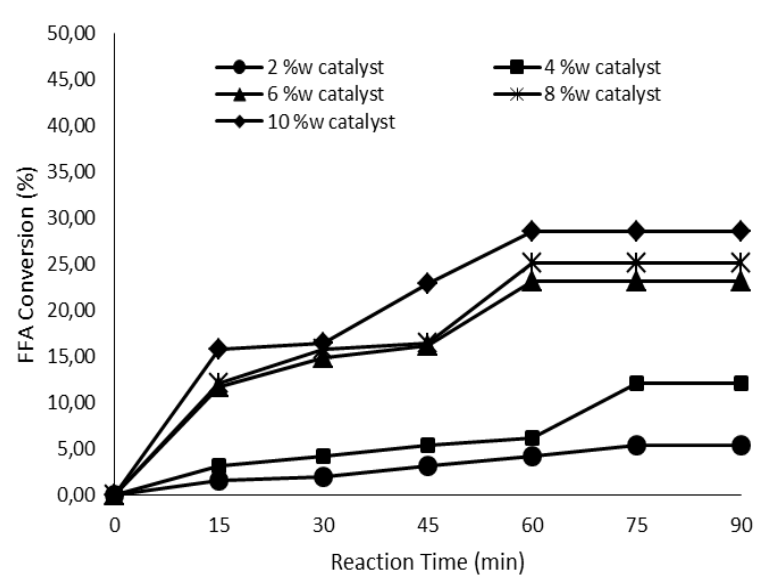

Fig. 2. The Effect of Catalyst Amount on FFA conversion 


\subsection{The Effect of Co-solvent Amount}

The solubility of methanol in oil is low. The co-solvent is added to the reactor to increase solubility methanol in oil and speed up overall reaction time. In this paper, THF is used as co-solvent for biodiesel production. The ratio of THF to oleic acid was varied at concentrations of $2,4,6,8$ and $10 \%$. It is noticeable that by adding THF to the reaction mixture, increase the FFA conversion. The higher the THF concentration, the FFA conversion also increases. This suggests that THF as a co-solvent can increase overall reaction time due to the increase of oleic acid miscibility in methanol which leads to increase overall reaction time $[13,16]$. The increasing speed of the overall reaction is due to the addition of THF which makes the oil and methanol in one phase as shown in the ternary diagram of Fig. 4.

At THF concentration to the oleic acid of $2 \%$ only resulted in maximum FFA conversion of $7.24 \%$ while at $4 \%$ and $6 \%$ THF concentration resulted in FFA conversion of $22.93 \%$ and $24.11 \%$ respectively. By increasing the concentration of THF to $8 \%$ and $10 \%$, the FFA conversion yield $28.57 \%$. This indicates that the THF concentration of $8 \%$ is the optimum concentration since the FFA conversion at $10 \%$ THF is the same.

At low THF concentration (2\%, 4\% and 6\%) FFA conversion was a steady state at a reaction time of 75 minutes while at THF concentration above $8 \%$ FFA conversion had reached steady state at a faster reaction time of 60 minutes. Therefore, the optimum THF concentration was at $8 \%$.

\subsection{The Effect of Reaction Temperature}

The reaction temperature dramatically influences the conversion of the reaction. The higher the reaction temperature, the collisions that occur between the reactant particles are higher, causing the reaction to be faster and the conversion increases [11, 12]. In this esterification reaction of oleic acid catalyzed by Amberlyst 15, the reaction temperature was varied from $30{ }^{\circ} \mathrm{C}$ to $60{ }^{\circ} \mathrm{C}$. The reaction temperature should be below $64{ }^{\circ} \mathrm{C}$ because at temperatures above $64{ }^{\circ} \mathrm{C}$ the methanol will evaporate, causing contact between methanol and oleic acid to be reduced.

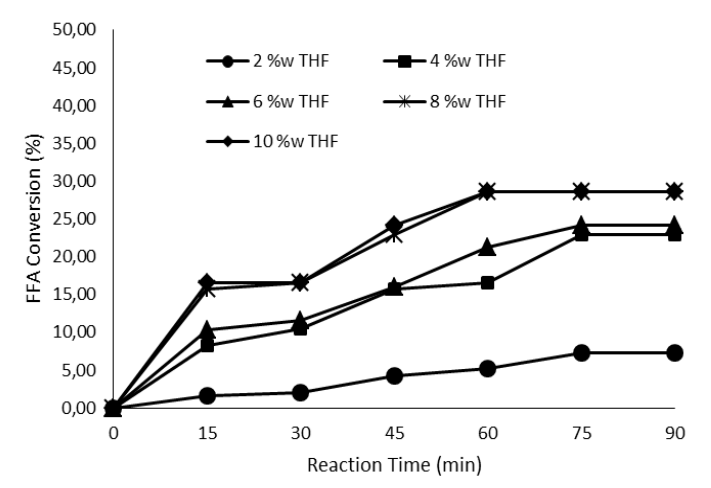

Fig. 3. The Effect of Co-solvent Amount on FFA conversion

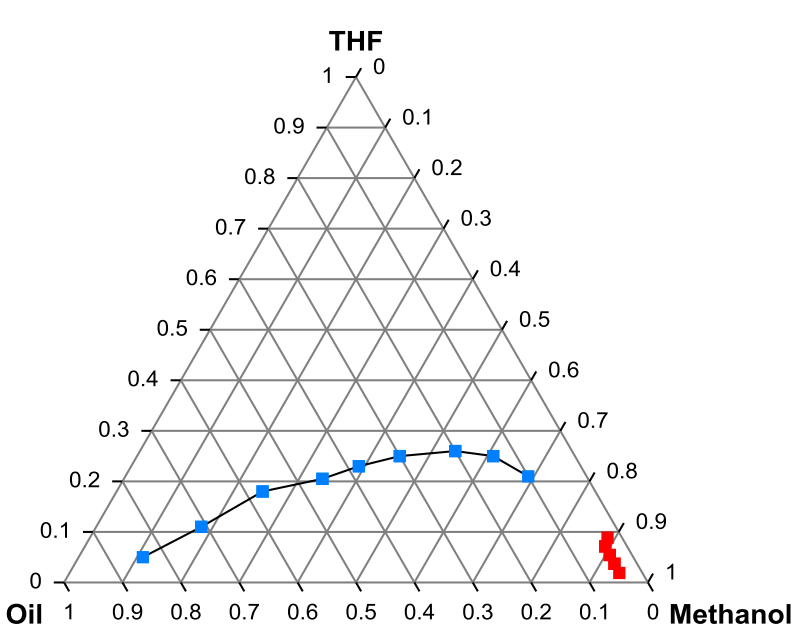

Fig. 4. Terner Diagram of THF, Methanol and Oil. Boocock Research. This Research

From Fig. 5, it can be inferred that the reaction temperature greatly affects the conversion of FFA in oleic acid esterification. Fig. 5 illustrates the conversion of FFA with the interval 15 minutes at reaction time for 90 minutes. It is clear that the higher the reaction temperature, the greater the conversion of the FFA. At low temperatures $\left(30^{\circ} \mathrm{C}\right)$, the conversion of FFA is very low at $2.3 \%$ under steady state. This indicates that at the low reaction temperature, the oleic acid esterification is difficult. By increasing the reaction temperature to $40^{\circ} \mathrm{C}$ and $50{ }^{\circ} \mathrm{C}$, there was an increase of FFA conversion by $9.16 \%$ and $17.78 \%$ respectively. The highest FFA conversion is achieved at 60 with FFA conversion of $28.57 \%$. In all variations of the reaction temperature, the steady state conditions were reached after 60 minutes.

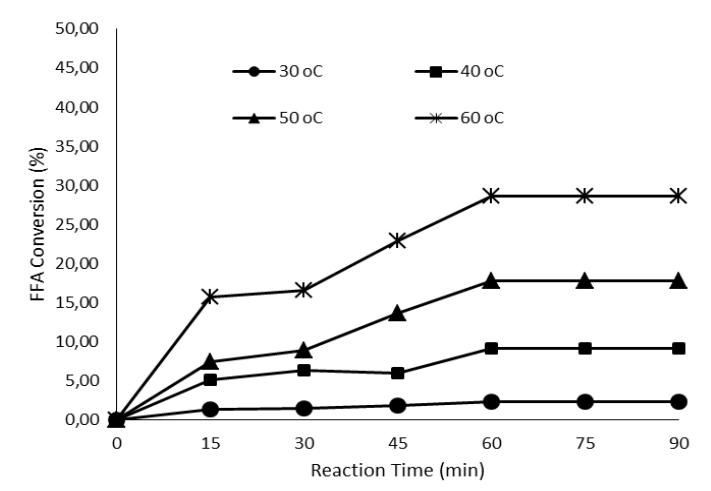

Fig. 5. The Effect of Reaction Temperature on FFA conversion

\subsection{The Effect of Catalyst Reuse}

One of the advantages of heterogeneous catalysts is an easy separation process and can repeatedly be used. In this study, the heterogeneous catalyst used was Amberlyst 15 . The catalyst was repeatedly used in oleic acid esterification to test the Amberlyst 15 performance. In this study, the used catalyst was reused 5 repetitions to see the performance of the catalyst regarding repeated use of FFA conversion $[12,16]$. 
It can be concluded from Fig. 6 that the use of Amberlyst 15 in the esterification reaction of oleic acid shows a good performance. FFA conversion in steady state conditions did not decrease significantly after the fourth usage. After the fifth usage, there was a significant reduction of FFA conversion from $23.07 \%$ to $15.42 \%$. This indicates that the Amberlyst 15 must undergo regeneration after being used 4 times. In addition, the decreasing of conversion was possibly due to adsorption of water produced during esterification and blocked the pores of the catalyst and inhibits the catalytic activity. [17].

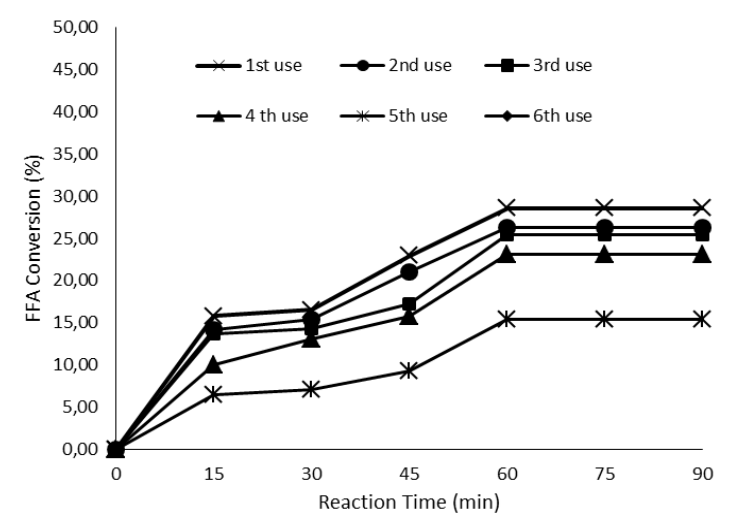

Fig. 6. The Effect of Catalyst Reuse on FFA conversion

\section{Conclusions}

The conversion of free fatty acid significantly increases by the involvement of THF as a co-solvent. The highest FFA conversion of $28.57 \%$ was obtained using molar ratio methanol to the oleic acid of $25: 1$, the catalyst of $10 \% \mathrm{w} / \mathrm{w}$, THF concentration of $8 \%$, and a reaction temperature of $60^{\circ} \mathrm{C}$. The steady state was achieved after 60 minutes. The catalytic activity was maintained after four repeated use.

We would like to thank to the Ministry of Technology Research and Higher Education of Indonesian Government for financial support to the research.

\section{Reference}

1. G. Baskar, R. Aiswarya, Renewable and Sustainable Energy Rev., 57, 496-504 (2016)

2. B. R. Moser, Dev. Biol. Plant 45, 229-266 (2009)

3. A. Harvey, J. G. Lee, F. H. Kasim, E. J. Eterigho, J. Sci. Ind. Res., vol. 17, 822-828 (2012)

4. L.F. Gutierrez, O.J. Sanchez, C.A. Cardona, Bioresour. Technol. 100, 1227-1237, (2009)

5. P. Nakpong, S. Wootthikanokkhan, Renewable Energy 35, 1682-1687, (2010)

6. N. Ozbay, N. Oktar, N. A. Tapan, Fuel, 87, 1789 (2008)
7. D. M. Chesterfield, P. L. Rogers, E. O. Al-Zaini, A. A., Adesina A., Procedia Eng. 49, 373 - 383 (2012)

8. J. F. Oliveira, I. L. Lucena, R. M. Saboya, M. L. Rodrigues, Renewable Energy 35, 25812584,(2010)

9. D. G. B. Boocock, S. K. Konar, V. Mao, H. Sidi, Biomass Bioenergy 11, 43-50. (1996).

10. S. Sulaiman, A. R. Abdulaziz, M. K. Aroua, J. Taiwan Inst. Chem. Eng. 44, 233-238. (2013)

11. N. B. M. Yunus, N. A. B. Roslan, C. S. Yee, S. Z. Abidin, Procedia Eng., 148, 1274 - 1281 (2016)

12. A. M. Doyle, T. M. Albayati, A. S. Abbas, Z. T. Alismaeel, Renewable Energy, 97, 19-23 (2016)

13. D. G. B. Boocock, S. K. Konar, V. Mao, H. Sidi, J. Am. Oil Chem. Soc. 73, 1247-1251, (1996)

14. Y. J. Cho, T. E. Kim, B. Kill, Food and Science Technology, 53, 517-521(2013)

15. A. Hykkerud, J. Marchetti, Biomass and Bioenergy, 95, 340-343, (2016)

16. I. F. Nata, M. D. Putra, C. Irawan, C. K. Lee, J. Environ. Chem. Eng. (2017).

17. E. Andrijanto, E. A. Dawson, D. R. Brawn, Appl Catal B 1145, 115-116 (2012) 